Publicación semestral. ISSN 2215-4906

Volumen 79 - Número 1

Julio - Diciembre 2019

\title{
La dramaturgia costarricense ¿contemporánea? escrita por mujeres: un balance historiográfico del periodo 2000-2017
}

\author{
The ¿Contemporary? Costa Rican Dramaturgy \\ Written by Women: a Historiographical Balance of the \\ Period 2000-2017
}

Elvia Amador Rojas

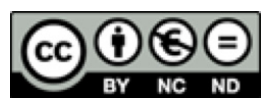

Esta obra está bajo una licencia Creative Commons Reconocimiento-No comercial-Sin Obra Derivada 


\title{
La dramaturgia costarricense ¿contemporánea? escrita por mujeres: un balance historiográfico del periodo 2000- 2017
}

\author{
The ¿Contemporary? Costa Rican Dramaturgy \\ Written by Women: a Historiographical Balance of the \\ Period 2000-2017
}

\author{
Elvia Amador Rojas ${ }^{1}$ \\ Universidad de Costa Rica \\ Costa Rica
}

Recibido: 17 de octubre de 2018 Aprobado: 17 de enero 2019

\begin{abstract}
Resumen
Este texto se propone realizar un balance de la manera en que ha sido estudiada, entre el 2000 y el 2017, la dramaturgia costarricense escrita por mujeres, un lapso que permite enmarcar la relevancia del papel de la mujer en la producción/construcción de discursividad y de sentido. Donde la escritura teatral nos cuestiona sobre lo contemporáneo y lo femenino de estas construcciones sociales.
\end{abstract}

Palabras clave: dramaturgia costarricense; autoría femenina; teatro contemporáneo; historiografía

\begin{abstract}
This text intends to take stock of the way in which the Costa Rican dramaturgy written by women has been studied from 2000 to 2017, a period of time that allows to frame the relevance of the role of women in the production / construction of discourse and sense. Where the theatrical writing questions us about the contemporary and the feminine of these social constructions.

Keywords: Costa Rican dramaturgy; female authorship; contemporary theater; historiography

1 Docente de la Escuela de Estudios Generales y de la Escuela de Artes Dramáticas de la Universidad de Costa Rica (UCR). Licenciatura en Artes Dramáticas por la UCR. Correo electrónico: elviaamador@gmail.com
\end{abstract}




\section{Introducción. Lo contemporáneo, la mujer y su teatro}

La lengua poética tiene una relación peculiar, muy propia, con la verdad. Eso se muestra, en primer lugar, en que no se adecua en todo tiempo a cualquier conteni-

do; pero también, en segundo, en que siempre que tal contenido adquiere la figura de la palabra poética, experimenta una especie de legitimación. Es el arte del lenguaje el que decide, no sólo sobre el éxito o el fracaso de la poesía, sino también sobre su pretensión

de verdad

(Gadamer, 2011, p. 111)

Las posiciones epistémicas del poder como únicas categorías analíticas para el arte de las mujeres han sido fuertemente criticadas por diversos autores en el presente siglo. Aunque se podría suponer que las mujeres, como sujetos, hemos sido irremediablemente marcadas por las condiciones de nuestros contextos, parece no ser muy útil pensar que la posición epistémica de la marginalidad sea, en resumen, el potencial artístico de las mujeres para expresarse desde la escena, ¿o acaso lo es?

Esta historiografía propone un balance sobre la manera en que ha sido estudiada, entre el 2000 y el 2017, la dramaturgia costarricense escrita por mujeres, proponiendo como enfoque de su análisis la relación entre lo contemporáneo, la mujer y el teatro, en el abordaje de los estudios existentes con respecto a la dramaturgia costarricense de autoría de mujeres. Asimismo, se problematiza el concepto de contemporáneo, ya que enmarca el tema que aquí nos convoca debido al lapso seleccionado. Por lo tanto, se procede a revisar la relación que existe entre el concepto de contemporáneo y el fenómeno teatral, para abordar, con mayor lucidez, las posiciones desde las cuales se estudia la dramaturgia costarricense escrita por mujeres entre 2000 y 2017. La delimitación ubica los últimos escritos sobre dramaturgia costarricense contemporánea de mujeres y que no han sido estudiados con anterioridad. Aunque son muy pocos, permiten esclarecer los principales antecedentes de la dramaturgia costarricense contemporánea escrita por mujeres y, por tanto, acercarnos a la comprensión de este fenómeno desde su relación con su contexto, búsquedas estéticas o construcciones semióticas.

En términos del historiador y teórico del arte B. Wyss (2010), el arte funciona como productor de tiempos al depender de la materialidad, pero está en disputa con lo que debe o quiere cambiar el ser humano de sus relaciones (de poder). Esta cualidad del arte de visitar otros tiempos desde el presente; de invocar otros tiempos incluso futuros, hace que la propia concepción del sujeto frente a esa experiencia pueda ser modificada. Le evidencia 
los síntomas del padecimiento, carencia o bien la grandeza de una sociedad, para conocer el camino del cambio. Es esta cualidad del arte la que nos hace dudar sobre el discurso de "lo contemporáneo" y la misma razón por la cual la lente de la exclusión de la mujer también se desdibuja como única línea analítica frente al arte de las mujeres.

Para asomarnos al concepto de contemporáneo revisaremos la posición de Patrice Pavis, uno de los teatrólogos más influyentes de nuestra época, por cuanto se ha dado a la tarea de fundamentar, entre otros textos, dos diccionarios especializados de teatro. En su definición de lo contemporáneo, contenida en su Diccionario de la performance y del teatro contemporáneo (2016), Pavis ubica al teatro como su escenario, propone al teatro como productor de tiempos, por lo que se problematiza este concepto, al indicar que, "en esta hora de la globalización, ¿no son contemporáneas todas las sociedades y todos los grupos?" (p. 61). Continúa proponiendo las distintas acepciones que surgen del término contemporáneo como adjetivo de teatro: el teatro en sus procesos recientes, en oposición al arte "moderno" (correspondiente a las vanguardias del siglo XX), también como "aquello que acaba de superar el pasado y se constituye como un presente palpitante" (p. 61). Ante esta disyuntiva, Pavis propone buscar una definición no normativista, ver lo contemporáneo como la capacidad de renovar el presente y así concluye desde la lente del autor Giorgio Agamben para su encuadre:

El teatro es el escenario mismo de lo contemporáneo, porque "el presente no es sino la parte de lo no vivido en todo lo vivido". Sobre el escenario, lo que actuamos y lo que percibimos es, al mismo tiempo, lo que buscamos mostrar o descubrir y lo que se nos escapa, lo que no conseguimos vivir (Pavis, 2016, p. 62).

Para el presente análisis se parte de la problematización de la escritura de mujeres en el marco teatral como fenómeno contemporáneo y, por tanto, se dividirán las revisiones de las fuentes de acuerdo a su abordaje de estos conceptos. Es en el escenario (espacio de representación) donde lo que se actúa y lo que se percibe es, a la vez, lo que deseamos revelar y lo oculto en ello. En este sentido, se presume que la dramaturgia de autoría femenina costarricense aborda distintas maneras de representar el mundo en una búsqueda de nuevos espacios que ocupar, lugares de enunciación que le permitan habitar el espacio del discurso, construyendo alternativas a la propuesta del discurso hegemónico-patriarcal. Pero vale la pena preguntarse si es posible escapar a la emisión de un juicio político, es decir uno planteado en el ámbito de lo público, en tanto mujer enunciante de una posición. Este artículo parte de las siguientes preguntas: ¿cuáles son los discursos generados sobre la dramaturgia costarricense escrita por mujeres en la alborada del siglo XXI? ¿cómo están construidos esos posicionamientos? 


\section{Historia y teatro}

Se encuentra como una primera categoría de análisis de la escritura teatral de mujeres entre 2000 y 2017, el enfoque histórico, que pretende investigar el teatro en tanto acontecimiento social en el marco de la tradición, es decir en un plano amplio de la cultura. Este enfoque parece permitir la ubicación del fenómeno teatral con relación a su contexto de producción, recuperando las propuestas temáticas y relacionando las diferentes búsquedas estéticas con un contexto epistémico, como se postula a continuación.

El investigador y teatrista Juan Carlos Calderón en el texto Aportes para una historiografía del teatro costarricense: ¿Cómo y desde qué perspectiva se ha escrito la historia del teatro en nuestro país? (2004) expone la ausencia de estudio historiográfico hacia el fenómeno teatral en general. Calderón se propone evidenciar que las formas narrativas para tratar el fenómeno teatral han acudido "a criterios meramente literarios y biográficos o a relaciones ideológicas del texto con las estructuras de poder y no con la concreción del hecho dramático, como lo es la puesta en escena" (p. 63). Este autor trabaja con un corpus cerca de diez textos, a través de los cuales mira el desarrollo de la historia teatral costarricense hasta el año 2000, donde inicia el presente balance.

Enfatiza Calderón que existe la necesidad de escribir la historia del fenómeno teatral, no solo desde el plano literario, sino más bien, desde la puesta en escena y en articulación con el ámbito más amplio de la cultura, ya que también, propone la crítica teatral como un posible colaborador en este tipo de recuperaciones o valoraciones desde el campo de la historia. Es evidente, para este autor, que el teatro no se puede estudiar únicamente como un fenómeno "de lo social" sino que a lo interno de la técnica escénica y sus estrategias falta desarrollar herramientas de análisis. Es decir, abordar el teatro como acontecimiento, desde las concepciones que el mismo teatro sugiere. "Al ser un hecho efímero, exclusivo en su representación, es complejo su estudio. Tal vez ésta [sic] sea la causa de los pocos estudios que se han realizado" (p. 67). Calderón apunta dos elementos sugerentes en el encuentro a nuevas posibilidades historiográficas:

1 La posibilidad de tomar en cuenta otros materiales aparte del texto literario, como programas de mano, afiches, fuentes audiovisuales, planos, diseños, libro de dirección, documentos de los actores, entre otros.

2 La necesidad de un "Centro de Documentación para las Artes Escénicas" o similar. Es decir, una entidad especializada en el campo que apoye su estudio. 
Por su parte, la historiadora Patricia Fumero, que ha dedicado buena parte de sus investigaciones a estudiar el fenómeno teatral en Costa Rica, en su artículo Los Caminos de la Dramaturgia Costarricense (2007) posiciona, a través del lente de Bourdieu, la importancia de la historia de un campo para acercarse a su comprensión, en este caso, rescata la labor de la historia para comprender la conformación del teatro costarricense. Es importante para la lectura de Fumero destacar el enfoque de Bourdieu, quien encuentra en el proyecto Moderno la causa del sufrimiento, la exclusión social y las desigualdades; ya que, como se reparará, Fumero también ubica este fenómeno de la Modernización como causal de una serie de transformaciones importantes para el desarrollo del teatro costarricense.

Propone, la autora, cuatro puntos fundamentales para abarcar la historia del teatro costarricense: la profesionalización, el cambio en el paradigma de la producción teatral en Costa Rica, el proceso de búsqueda identitaria de la dramaturgia costarricense y la institucionalidad cultural. Según analiza Fumero (2007), todos esos puntos están inscritos en el surgimiento del Estado y la ideología que le soporta, hechos sin duda atravesados por el avance del proyecto Moderno. En el siglo XIX, Costa Rica, con el amparo de las políticas culturales del Estado, ya tenía la infraestructura teatral necesaria para responder a las exigencias culturales de los modelos europeos, posibilitando presentaciones internacionales. También, ya a principios del siglo XX, se contaba con una generación de prolíicos dramaturgos, valga recalcar que no se menciona ninguna dramaturga. Actualmente, con la inminente presencia de la Modernidad, determinada por la cultura de masas, por un lado, se desfavorece el teatro al contar ahora con la competencia del cine, pero, por otro, se beneficia, gracias a la difusión que la radio posibilita.

Por su parte, la profesionalización en el teatro costarricense se hace posible gracias a dos elementos esenciales, según expone Fumero. Primero, las inmigraciones de actores y directores profesionales de otras latitudes, que como conocemos tiene una fuerte carga del fenómeno global de la época (principios del siglo XX). Y segundo, la creación de la Universidad de Costa Rica (1940) que promueve las representaciones estudiantiles que dan paso a futuras imbricaciones profesionales y no profesionales que culminan en la conformación de la Escuela de Artes Dramáticas de la misma Universidad.

Volviendo al tema estatal, después de la Guerra Civil (1948), debido a las políticas culturales que se desarrollaron se da una disyunción en el tratamiento de la realidad costarricense y se dejan los estereotipos del costumbrismo, para privilegiarse la dramaturgia. De acuerdo con Fumero (2007), esto se realiza con pretensiones universalistas y determina a 
los tres autores más influyentes de la dramaturgia costarricense en adelante: Alberto Cañas (1920 -2014), Samuel Rovinski (1934 -2013) y Daniel Gallegos (1930 -2018). En la dramaturgia de estos autores "se encuentra la representación de dos de los mitos fundacionales de la patria: la homogeneidad racial y la democracia rural” (p. 87).

Podemos leer aquí, un esfuerzo estatal por entrar a competir en este marco global de la Modernidad, pues se mencionan también otros autores y autoras teatrales que tuvieron poca influencia y reconocimiento por estar "no alineados ideológicamente al proyecto político-cultural vigente en ese momento" (p.86). Esta es la primera mención que se hace a mujeres escritoras de teatro como Carmen Naranjo (1928 -2012), Victoria Urbano (1926 -1984), Lupe Pérez (1922- 2017) y otras autoras que figuran en este grupo de los que fueron invisivilizados por las políticas culturales del Estado y que son piezas fundamentales para la comprensión de la historia de la dramaturgia escrita por mujeres. Este velo puesto sobre su escritura también parece importante para ubicar el desarrollo de esta dramaturgia.

En 1980, con la instauración de las estrategias neoliberales, las políticas culturales del Estado hacia el teatro cambian y las presentaciones disminuyen a lo indispensable para no desaparecer las instituciones establecidas (Compañía Nacional de Teatro y Escuelas Universitarias). Este antecedente es fundamental en la historia del teatro costarricense pues da pie al teatro empresario, según apunta Fumero. A partir de esta crisis, según la autora, surge el grupo llamado la Nueva Ola y que procura una "renovación escénica al incorporar nuevas problemáticas como son: la dignidad humana, las reivindicaciones y las relaciones de género, la violencia familiar, la libertad y la justicia social, entre otras" (p. 87). Esta generación de dramaturgos y dramaturgas reflexiona también sobre la función del teatro y adquieren un compromiso social: "intentaban desarrollar una conciencia colectiva de los problemas que enfrenta la sociedad en la cual se vive" (p. 87).

Continúa el texto exponiendo que, pese a las dificultades que enfrenta este grupo por el poco apoyo editorial para sus textos y la desventaja económica de la producción independiente, consiguen reconocimiento y consolidación, lo cual implica una mayor madurez del medio teatral costarricense. Según Fumero (2007), a partir de este momento, ya desde 1990, surge una nueva transformación debida a la posmodernidad y a la madurez del sistema capitalista, donde el teatro encuentra nuevos retos en la creación de discurso a partir de la conciencia de la diversidad y sus consecuencias sociales. Para Fumero (2007), las coordenadas epistemológicas subyacentes a los lenguajes artísticos se pueden ver subyugadas, como en el pasado, a las propuestas o necesidades de las políticas culturales 
estatales. Por lo que la institucionalidad representa, según propone la autora, un posible desafío para la generación "De la Nueva Ola", ahora en capacidad de liderarla. Capitalizando los aportes del recorrido de Fumero (2007) hacia la presente historiografía, es importante comprender estas dinámicas donde la búsqueda de una identidad propia entra en tensión con una construida por intereses estatales. Además, el factor económico subyuga la creatividad y las necesidades expresivas a la "benevolencia" de los teatros empresariales que privilegian el lenguaje económico sobre el artístico, donde la complejidad del mundo globalizado obliga a los artistas a habitar la institucionalidad para la subsistencia. Lo anterior forma el marco en el que construyen sus propuestas las dramaturgas del año 2000 al 2017.

Los enfoques de Calderón y Fumero, aunque distintos no son excluyentes. Para estudiar un fenómeno fugaz y vivo como el teatro, es importante comprender el contexto en el cual se desarrolla su discurso. Pues, muchas veces el contexto condiciona a tomar formas determinadas, pero por otro lado, para que sea posible su análisis se requiere contemplar esta particularidad que es la temporalidad, es decir que su delimitación está dada por los mismos términos que definen a la contemporaneidad. A partir de este análisis histórico parece inevitable la pregunta ¿qué relación guarda la dramaturgia contemporánea con las políticas culturales del estado? La pregunta se refiere a la búsqueda del seguimiento de este aparente patrón, en la sospecha de que haya cambiado, sea por las búsquedas que la dramaturgia se plantea a nivel estético o sea porque el estado dejó de percibir como relevante tener incidencia en las manifestaciones teatrales.

\section{Fragmentando el origen de la dramaturgia contemporánea}

El investigador, Luis Lázaro (2014) en su artículo Mito, género y empresa, tres imágenes originarias de la dramaturgia contemporánea costarricense, presenta una dificultad para comprender su tesis y es su posicionamiento confuso del objeto de análisis, puntualmente en cuanto a su delimitación. Lázaro trae a colación el concepto de lo contemporáneo y enmarca su estudio en "tres imágenes fragmentarias sobre el origen de la dramaturgia costarricense desde lo contemporáneo" (p. 7). Introduce los obstáculos que existen para estudiar el fenómeno de la dramaturgia costarricense contemporánea porque encuentra un gran vacío en los antecedentes históricos de la dramaturgia nacional. Este hecho lo conduce a valorar el papel del Estado y su configuración fundacional como culpable, tesis que había sido abordada por otros autores acotados anteriormente. El texto de Lázaro esboza tres características de la dramaturgia nacional:

1 Carece de mitos fundacionales: al haber borrado la historia indígena del país, las características autóctonas de lo ritual y su posible teatralidad se desconocen. 
2 La escritura de la mujer es "tardía" en un primer momento de la lectura, pero luego señala la censura y segregación que han sufrido las dramaturgas nacionales históricamente.

3 La escritura dramática surge por intereses políticos y empresariales más que artísticos.

Según el autor, el grupo hegemónico dispuso, luego de la independencia, una base de tradición y referencia europea para la fundación de la República una vez que se tuvo el capital que proveyó el café. También, el consolidar la educación como secularización de la iglesia, pues esta constitución fundamental actúa como arma para verter las ideas liberales y positivistas de los intelectuales que se dieron a la tarea de escribirnos una identidad nacional. De esta forma, concluye el autor que la esencia de los antecedentes históricos de la dramaturgia nacional es la exclusión. La exclusión instaurada por el mito de que Costa Rica es blanca, cristiana católica, educada, productora de café, insular y única. Del mismo modo plantea la exclusión femenina como elemento constitutivo u originario de la dramaturgia contemporánea. Sin embargo, esta conclusión es cuestionable y no parece constituir un balance histórico, sino más bien, una percepción o un punto intuitivo de partida para indagar, ya que esta conclusión parte de la siguiente posición ofrecida por Lázaro:

La baldosa histórica que colocó el proceso de la colonia y la construcción de la República durante todo el siglo XIX, surtió su efecto. Nos dejó desnudos y sin referentes, es una historia conocida que los pueblos originarios de nuestra América, fueron asociados, por los grupos hegemónicos, a la barbarie y al atraso. A partir de aquí se les ubicó en el lugar social de la servidumbre. Como el material humano dispuesto a ser dominado, explotado, mestizado y evangelizado, es decir, rescatado de su propia ignominia (2014, p. 10).

Hoy sabemos que los entretejidos del lenguaje manifiestan esta mezcla cultural que se dio en tiempos de la conquista y que las construcciones culturales son complejas en cuanto a esta etapa en toda "nuestra América". Sin embargo, existen estudios sobre rituales indígenas anteriores y de este periodo que se ignoran en la ponencia de Lázaro, por ejemplo, Castro y Guevara (2015), en el texto "El baile de los diablitos en Boruca: Magia vs Dominación", revisa investigaciones que elaboran un rastreo de algunas manifestaciones como danzas, representaciones teatrales indígenas y los conocidos bailes de conquista que evidencian un problema en cuanto a la percepción de Lázaro y es que el no practicarse, o conocerse, no imlica que algunas de estas manifestaciones no influencien o circunscriban nuestras prácticas actuales. Parece que existe aquí una oportunidad de esclarecimiento 
más que un señalamiento fundamentado al decir que "carecemos de una mitología originaria y fundacional, en lo que al teatro corresponde" (Lázaro, 2014, p. 9). Del mismo modo parece apresurada su posición sobre el género al sostener, a partir de un cuadro de dramaturgos nacidos entre 1840 y 1932 encontrado en el libro de Quesada, Ovares, Rojas, Santander, Antología del teatro costarricense (1993) que utiliza Lázaro como referencia, que:

Este es el abismo: la escritura femenina fue tardía y, en cierto sentido, censurada, si pensamos que Carmen Lyra fue obligada al exilio en 1949. Por tanto, se puede decir, que la primera dramaturga del país sufrió la discriminación de género como también la exclusión política y el exilio (Lázaro, 2014, p. 14.)

Este aspecto no parece crucial o diferenciador con respecto al resto del mundo, por lo que no parece válido como característica fundamental para determinar la dramaturgia contemporánea. El mismo autor expone la exclusión de la mujer de la época tanto de la labor política como de la propiedad económica, por lo que este aspecto parece una característica del contexto que podría ser punto de partida para investigar las implicaciones de este hecho en la dramaturgia costarricense. Sin embargo, la discriminación de género es parte del patriarcado en todo el mundo y no un aspecto que se pueda valorar como una característica originaria de la dramaturgia local. En todo caso, lo que parece funcionar como indicador fundamental es la forma en la que la escritura de mujeres logra integrarse o proponer un discurso a partir de lo establecido.

En el último punto coincide con Fumero (2007) al exponer el surgimiento de la escritura dramática con relación a los intereses políticos de definir una identidad para el Estado. Asimismo, presenta los intereses empresariales más que artísticos al cambiar el modelo económico en la década de 1980. No obstante, en el caso de Lázaro se enfatiza en la exclusión como elemento determinante de la dramaturgia, elemento que extrae a partir de estos factores históricos.

Cargados de los modelos europeos se ocuparon con fe y determinación en inventar una identidad nacional capaz de contener y soportar la idea de un pasado idílico muy cercano a la igualdad, la concordia y la respetabilidad de las buenas maneras. Aun [sic] cuando ello fuera a costa de la exclusión de aquellos que no compartían su catálogo ideológico o sencillamente ocupaban la posición subalterna de todo su proyecto político (Lázaro, 2014, p. 17).

Ubica la exclusión como resultado de la mezcla de ideología y negocios de los grupos de poder permeados por el liberalismo y el positivismo. Termina por criticar el presupuesto estatal para cultura y arte exponiendo que el modelo que se siguió marcó una división social del trabajo político y cultural de tal forma que el teatro continúa siendo subsidiado por el 
poder político. Esta problematización no se articula con los objetivos de la investigación y no se valoran estas posiciones con relación a la escritura dramática, se evalúan algunos aspectos contextuales, pero no se establecen luego dentro de la dramaturgia planteamientos que evidencien estas posiciones.

\section{Una propuesta desde la búsqueda estética de la escritura de la mujer: lo siniestro}

El escritor e investigador independiente, Rodrigo Soto, en el texto Lo siniestro y el cambio de modelo político en Costa Rica: tres obras teatrales de autoras contemporáneas (2014), analiza a través tres obras teatrales escritas por mujeres costarricenses, a saber: Dicen las paredes (2009), de Aylin Morera, La loca (2010) de Ana Istarú y Pentadrama (2012) de Claudia Barrionuevo y Walter Fernández. Se dispone a analizar tales piezas teatrales a través, fundamentalmente, de dos conceptos: "lo siniestro" a partir de los autores Schelling y Freud y el concepto de "mito de excepcionalidad costarricense" que el propio autor acuña.

Para iniciar, Soto brinda un breve análisis del contexto costarricense en aras de esclarecer posibles relaciones que se establecen con la producción dramática, en la misma línea que Fumero y Lázaro, a la luz del cambio de modelo político costarricense entre la última década del siglo XX y la primera del siglo XXI del Estado benefactor al neoliberal. En la propuesta de Soto, este cambio en el paradigma político en Costa Rica se identificó por la apertura de mercados y la implementación de políticas sociales focalizadas y asistencialistas. De forma paralela a estos cambios, este autor propone los grandes escándalos políticos por actos de corrupción que debilitaron el bipartidismo y trajeron inestabilidad al sistema político costarricense como un elemento vinculante debido a la crisis del sistema político que tratan las obras de su corpus.

Con respecto a los filtros conceptuales que utiliza para su abordaje, el primero al que se refiere es el de lo siniestro, estableciéndolo en primera instancia a partir de Schelling como algo secreto que debió permanecer oculto. Igualmente, repasa la profundización que Freud realizó de esta provocación, donde lo problematiza por encontrarle una doble condición de familiar y conocido / oculto y desconocido. Soto resume el abordaje del concepto como sigue: "lo siniestro es aquello que, sin ser completamente ajeno a nuestro entorno familiar o doméstico, permanece latente u oculto y al mostrarse, transforma lo conocido en algo irreconocible, desconcertante y muchas veces aterrador" (Soto, 2014, p. 24)

Continúa Soto su encuadre del concepto a partir de Trías, quien agrega que lo siniestro es algo temido, pero secretamente deseado por el sujeto, y que súbitamente se hace realidad. A partir de esta lectura de este concepto, Soto concluye que lo siniestro expone lo 
que se he mantenido en silencio y se presenta como un gesto social del miedo, esto guarda paralelismo con su indicador de la crisis política costarricense, paralelismo que se encuentra en las obras. Es decir, este concepto se propone como una característica de la dramaturgia contemporánea, al menos en estos tres casos, al divisarla como operación estética. "Lo siniestro es un concepto eminentemente estético, es decir, referido a las representaciones de lo real antes que lo real mismo" (p. 24). Es decir, según Soto, la escritura para estas autoras es una forma de evidenciar el horror de la crisis política nacional y visibiliza un síntoma de una presencia mayor. Parece establecerse desde esta lectura y tomando en cuenta el análisis de histórico de Fumero (2007) y también la posición, aunque algo difusa, de Lázaro, una característica de la escritura femenina en Costa Rica, por lo menos en cuanto al teatro donde lo simbólico adquiere, vía representacional, carácter de realidad.

Finalmente, el autor propone el concepto del mito de excepcionalidad costarricense como un complejo discursivo insertado en el imaginario nacional y componente importante de la identidad del país. Señala el autor que las tres obras en estudio pertenecen a una corriente literaria que desde un discurso contra hegemónico expone lo siniestro para simbolizar el cambio de modelo político en nuestro país. Por lo que, el mito de excepcionalidad costarricense parece un componente fundamental de análisis en tanto borra de la historia una serie de posiciones, subculturas, facetas que son borradas o silenciadas incluyendo a la mujer como figura política. Este abordaje es el mismo propuesto por Fumero en su análisis donde la construcción identitaria también se sustenta en los mitos fundacionales de la patria.

Podemos obtener como una primera conclusión que "lo siniestro" como característica de la dramaturgia está sustentado en la construcción estética que obedece a patrones contra-hegemónicos. El cambio de modelo político irrumpe en el imaginario y fractura estructuras sociales e individuales (psicológicas) relacionadas con la figura patriarcal y las garantías sociales, lo cual desencadena una serie de patrones e imágenes del horror generadas por la incertidumbre y el sentimiento de alienación, invasión y censura que el sistema propone para asegurar su éxito. Se encuentra aquí una característica fundamental de la dramaturgia contemporánea que se origina a partir de las búsquedas estéticas, en su esfuerzo por reconstruir la identidad costarricense a partir de la representación simbólica de la realidad que se oculta sin parecerlo.

Nos podemos cuestionar, a partir de esta disertación, si esta característica de lo siniestro, dentro de la escritura costarricense de mujeres, propone que todo discurso artístico de mujeres es de carácter contra-hegemónico y que, en las artes escénicas, al poseer la característica de "hacer presente lo ausente" donde se expone una realidad o una parte de 
la realidad de forma física y tangible, el gesto de lo siniestro está siempre implícito; o si es lo contemporáneo como gesto lo que propone esta operación y siguiendo los rasgos sugeridos es la mujer su máximo exponente.

\section{La deconstrucción de la imagen de la mujer tradicional costarricense como antecedente dramatúrgico: enfoque de género y semiótica}

La teatrista, escritora e investigadora Aylin Morera, en el texto La escritura femenina. Deconstruyendo imágenes (2006), investiga la construcción de imágenes femeninas planteadas en discursos contra-hegemónicos en la dramaturgia femenina costarricense desde finales de la década de 1950 hasta la de 1990. Contrapone las imágenes femeninas escritas por los dramaturgos Ricardo Fernández Guardia (1867 -1950), Alberto Cañas, Daniel Gallegos y Samuel Rovinski, expuestas por una investigación de la cineasta y escritora María Lourdes Cortés, quien se centra en cuatro obras donde se presentan imágenes femeninas "conformistas", acorde con el estereotipo cultural. Morera pretende analizar básicamente las temáticas y las propuestas de los personajes escritos por las dramaturgas a partir de finales de la década de 1950 y hasta principios del siglo XXI. La autora plantea la importancia de valorar el trabajo de la dramaturgia femenina en la construcción de un discurso trasgresor. Según la autora, la definición de los valores hegemónicos atribuidos a las imágenes femeninas en la literatura escrita por hombres es muy interesante ya que podría ser empleada como indicador de elementos discursivos constitutivos o heredados de la dramaturgia predominante $u$ oficializada.

Como parte fundamental del contexto costarricense, enfatiza la autora, en la importancia y el aporte de las dramaturgas Victoria Urbano y Lupe Pérez Rey, en tanto, plantean imágenes femeninas contestatarias. Señala que la omisión de su aporte tiene dos dimensiones: una propiamente en el ámbito de la literatura teatral por cuanto innovan en estructuras y temáticas, pero también en la construcción identitaria femenina alternativa desde la literatura. Prosigue recuperando la labor de algunas dramaturgas desde sus propuestas trasgresoras, haciendo la salvedad de que no todas las dramaturgas escriben desde esta posición, sino que también algunas lo hacen desde el discurso hegemónico, sea para ser aceptadas o, bien, por el arraigo que este discurso tiene en sus patrones de pensamiento. Según Morera, algunas de las imágenes femeninas propuestas por Lupe Pérez Rey, Leda Cavallini, María Silva, Ana Itstarú, Roxana Campos, Ishtar Yasin, Aylin Morera, Linda Berrón y Claudia Barrionuevo tienen en común la ausencia de descripciones físicas en pro de una valoración simbólica del cuerpo femenino en la que se da su rescate del discurso hegemónico que se lo apropia. 
La escritura dramática femenina en Costa Rica se caracteriza por construir nuevas imágenes femeninas, la de mujeres trasgresoras, que derrumban mitos y estereotipos. Mujeres con un cuerpo, no objeto del deseo, sino cuerpos llenos de significado desde el propio punto de vista femenino. En estos textos las descripciones físicas ni se nombran, porque lo importante es la experiencia humana como tal; se habla del cuerpo con el objetivo de rescatarlo del ultraje y de la dominación del "otro", y de la importancia de adueñarse como mujeres de sus propios cuerpos (Morera, 2006, p. 139).

Estas valoraciones se consideran pertinentes para analizar el discurso femenino en la dramaturgia costarricense contemporánea, ya que constituyen antecedentes fundamentales en la construcción de imágenes simbólicas desde la mujer, en oposición al discurso del poder. Cabe destacar el énfasis que se hace al trabajo con el cuerpo como tema, más que como elemento objetivizado. Por otra parte, en la operación narrativa se prescinde de descripciones en torno al cuerpo de la mujer, en una apuesta por un enfoque empírico más que perceptivo.

Por su parte, la historiadora e investigadora Deborah Cohen, en su texto ¿Para bien de... quién? La mentira, la manipulación psicológica y las relaciones afectivas en dos obras del teatro costarricense contemporáneo (2014), estudia el engaño y la oclusión como una metáfora de la crisis política costarricense en dos obras teatrales Dicen las paredes, de Ailyn Morera (2006) y Pentadrama, de Claudia Barrionuevo y Walter Fernández (2011), dos de las tres piezas teatrales analizadas por Soto (2014) de las que ya el presente texto guarda referencia. Cohen aborda los conceptos de la mentira y el engaño a través de la filósofa Sissela Bok y el psiquiatra Charles Ford. Ambos concuerdan en su enfoque desde la decepción como tema de fondo para dichas acciones. La autora establece una problematización de dos posibles conclusiones respecto a las obras:

las protagonistas se enteran de las verdades que sus queridos les han ocultado, ellas toman una decisión difícil, y al final, salen por encima de su pasado problemático y miran hacia un futuro lleno de posibilidades y de verdades. Pero a segunda vista, se podría concluir que estos triunfos personales, estos modelos de comportamiento realmente no lo son. En la versión de 2012, Gabriela prácticamente se suicida al dejar la casa de Bernal. Y para comenzar su nueva vida, Inés huye del país, en vez de enfrentarse con la justicia (Cohen, 2014, p. 10).

Retomando la visión de estos textos desde la propuesta de Soto, el ocultamiento de la verdad desde lo familiar -lo siniestro- parece el tema trascendental, en estas propuestas teatrales, es lo que se esconde detrás de un aire de naturalidad, lo que sostiene la tradición para la mujer. Asimismo, Cohen y Soto coinciden en que la mujer se ve subyugada por decisiones extremas o límites al enfrentarse a su verdad más íntima. La anagnórisis femenina 
representada en estos personajes es vinculante al contexto costarricense y los patrones del patriarcado que se simbolizan en las dramaturgias femeninas del presente siglo y desde el pasado. En este, las búsquedas estéticas de las escritoras estaban dirigidas a construir otras oportunidades para las mujeres costarricenses, nuevas formas de vivir su feminidad, de apropiarse de su mundo, oportunidades que al ser representadas se hacen posibles. Es entonces la deconstrucción de la imagen tradicional de la mujer, uno de los antecedentes más relevantes para la dramaturgia contemporánea, ya que permite, luego de jugar con las posibles construcciones representacionales de la mujer, apropiarse de nuevas posibilidades estéticas. Lo anterior sin tener que cumplir los mandatos del patriarcado con sus imposiciones a la mujer o, por lo menos, con la claridad de los patrones que se derivan de la estructura del poder.

Es importante aclarar que, aunque estas dramaturgas mencionadas por Soto y Morera escriben contemporáneamente, según apunta el mismo Soto, constituyen una generación de relevo entre la Nueva Ola y la actualidad. Las operaciones dramatúrgicas de estas escritoras, siguiendo las exposiciones de Fumero, Soto y Morera, constituyen una revelación feminista cuestionadora del paradigma del patriarcado amalgamado a los valores construidos para ser la imagen del Estado costarricense. Asimismo, la decisión de hacerse cargo de la imagen de la mujer construida en el teatro costarricense, apropiársela y diseñar nuevas posibilidades, dio pie a que la siguiente generación escribiera su apuesta estética en torno a otros valores, propuestos por el giro subjetivo, como se verá. Después de la generación de la Nueva Ola, que constituye un despertar de estos cuestionamientos y deconstrucciones sobre la imagen de la mujer, se puede escribir un teatro realmente contemporáneo. Contemporáneo en el sentido que propone Pavis, productor de sentidos y de temporalidades, donde se puede hacer presente lo ausente, donde lo siniestro se visibiliza para poderlo combatir, invocar otros tiempos, pues la mujer (por lo menos en la dramaturgia) no es más presa del tiempo del hombre.

\section{El cuerpo emergente de la mujer costarricense: la dramaturgia desde el giro subjetivo}

En su texto Femineidades emergentes: A propósito de emergencias: dramaturgia costarricense contemporánea emergente, Fumero (2008) trabaja sobre el análisis de tres obras de tres dramaturgas contemporáneas costarricenses: Elvia Amador (1981), Angie Cervantes (1980) y Milena Picado (1985), cuyos discursos, según Fumero, se presentan a partir de la deconstrucción, la disociación y la teatralidad como representación de los fenómenos sociales. Fumero trabaja con el enfoque de las construcciones de la subjetividad mediadas por la memoria y la historia social. 
las nuevas generaciones de mujeres no han terminado de expiar la culpa social que se les impone producto del sistema patriarcal. Estas obras, como otras anteriores, muestran la necesidad de re-articular la construcción de las subjetividades del pasado reciente y la construcción de la memoria, en este caso la historia social (Fumero, 2008, p. 87).

La autora señala como elemento temático "la culpa" instaurada en la mujer como parte de la imposición patriarcal y las relaciones interpersonales a partir de este elemento son dimensionadas a través del cuerpo como eje constitutivo de las narraciones. La teatralidad, es decir, la construcción de la diada espacio y tiempo se da desde el cuerpo como construcción social en las tres obras abarcadas por la autora.

En este aspecto, la investigadora Elaine Miller, cuando escribe Las contradicciones de ser mujer en Costa Rica en el siglo XXI en la dramaturgia emergente: El cuerpo femenino en Sinapsis (cuatro locas masticando a un imbécil) de Elvia Amador y 100 gramos de Janil Johnson (2011), observa en las dos obras que se propone analizar que la mujer debe cumplir con expectativas sociales contradictorias al tener que personificar la feminidad tradicional a la vez que ciertos valores asociados a lo masculino para triunfar en el ámbito laboral. A partir del concepto de autodisciplina acuñado por Foucault y las teóricas feministas Sandra Bartky y Susan Bordo, Miller expone la rebeldía del cuerpo en la construcción simbólica de las obras. Al referirse a los personajes de las obras señaladas apunta:

sus cuerpos son marcados por la maternidad, por ser objetos del deseo sexual masculino, por ser víctimas del abuso infantil o por participar en comportamientos autodestructivos. Dándose cuenta de la imposibilidad de conformarse a modelos de feminidad tradicional y mujer moderna, se rebelan (Miller, 2011, p. 126).

Para Miller, ambas obras construyen un discurso en que el cuerpo es una construcción social. Miller se ampara en Fumero (2008), a quien cita para destacar la tradición feminista presente en las dramaturgas emergentes donde temáticas polémicas como el aborto, la victimización de la mujer y la disgregación cuerpo-ser son retomadas a pesar de ser recurrentes desde la década de 1980, con la generación de la Nueva Ola. También, Miller (2011), destaca el aporte de estas dramaturgas y otros adscritos al Proyecto Teatral Emergencias por contener una visión joven de la realidad costarricense. La investigadora caracteriza estas propuestas teatrales de controversiales "por sus temas audaces, contenido violento y estructuras fragmentadas" (Miller, 2011, p. 126). Finalmente, Miller, determina estos elementos a través de su lectura aunada a la propuesta del teatrista e investigador Adolfo Albornoz, quien a su vez rescata la visión del filósofo, filólogo e investigador Werner 
Mackenbach, quien encuentra una misión política comprometida con la moral en la propuesta estética de los textos del Proyecto Teatral Emergencias donde la violencia sobre los individuos y sus relaciones personales ejemplifican dicho compromiso.

Estos señalamientos de Miller sobre la construcción discursiva, en cuanto a temática y estética, se anclan en las construcciones teóricas sobre la relación del cuerpo con el poder, al filtrarse la vida moderna y las expectativas sociales en la vida privada a partir del enfoque del cuerpo.

El poder que se ejerce sobre el cuerpo, el enfoque central de las obras de Amador y Johnson, ha sido analizado como un sistema de poder disciplinario por Michel Foucault. Estas prácticas disciplinarias, con la meta de producir cuerpos dóciles, no solamente se encuentran en instituciones como hospitales, escuelas y prisiones sino también en las actividades y costumbres cotidianas del individuo (Miller, 2011, p. 130).

Para Fumero (2008), las obras contemporáneas que estudia, donde una de ellas (Sinapsis: cuatro locas masticando a un imbécil de Elvia Amador) es también objeto de estudio de Miller (2011), proponen una necesidad de re articular la construcción de las subjetividades contemporáneas a partir de la reelaboración de la memoria social, de la interpretación del pasado. El olvido y la omisión de componentes incómodos del pasado, son ejes temáticos comunes a las tres propuestas abordadas y han sido tratados reiteradamente en la dramaturgia costarricense, según se sorprende la autora, en especial a partir del elemento constitutivo "cuerpo", en donde se vive a la vez el teatro y la teatralidad.

La discusión supone transformaciones sociales en las sociedades representadas, hoy en transición. En las producciones textuales el cuerpo, su apropiación y concepción, es considerado como una categoría teórico-cultural que materializa elementos como el abuso y la agresión física y emocional, el patriarcado, la violencia, la manipulación y las relaciones interpersonales (Fumero, 2008, p. 88).

Surge una hipótesis a partir de esta lectura en que se propone el discurso contemporáneo como una reivindicación del discurso femenino contra-hegemónico, pero también una evidencia de que la omisión de estos llamados de atención de la mujer históricamente se ha silenciado o invisivilizado, es decir, constituyen la evolución del mismo discurso. En este mismo sentido, las diferencias que percibe la autora con discursos anteriores son principalmente la utilización del cuerpo como espacio político de discusión y la búsqueda de la teatralidad (articulación de los componentes esenciales del teatro) en él. 
Es mediante el cuerpo, su uso y abuso que se comunican simbólica e imaginariamente los problemas que enfrentan los y las protagonistas, y por el cual se comunica la identidad, la memoria, el poder, la sexualidad y la victimización. El cuerpo, en estos textos, es a la vez teatro y teatralidad (Fumero, 2008, p. 88).

La exposición del cuerpo como espacio político y la culpa como elemento instaurado en el imaginario femenino para su control desde el discurso hegemónico parecen ser elementos importantes para la propuesta teatral contemporánea. El elemento "culpa", tiene una relación vinculante con el contexto histórico y el aspecto de lo siniestro, según ha sido abordado por autores como Soto y Lázaro, aunque en este último, lo siniestro se coloca más en torno a la exclusión como estrategia política.

\section{La dramaturgia escénica: la problemática de la corporización de la escritura para la investigación académica}

Pareciera que los antecedentes y la apropiación de la mujer contemporánea sobre su escritura han volcado los esfuerzos hacia un espacio de creación, más inclusivo, donde la dramaturgia escrita y la escénica cohabitan. No obstante, la dramaturgia escénica representa un reto para la investigación debido a que es un fenómeno efímero. Por ejemplo, en el ámbito académico encontramos tres proyectos finales de graduación, para optar por el grado de Licenciatura en Artes Dramáticas de la Universidad de Costa Rica, relacionadas con el estudio de la dramaturgia contemporánea escrita por mujeres. Estas investigaciones emplean un enfoque creativo y feminista en el abordaje para la construcción de una pieza teatral. Además, enfatizan, en los tres casos, la implementación de la dramaturgia escénica que constituye, según estas mismas autoras identifican, una tendencia en el presente siglo. Asimismo, los tres trabajos se enfocan en el interés de dialogar con la realidad desde la posición de la mujer como objeto y sujeto del discurso.

Estos trabajos son: iQué roja está la luna! (2010) de Elvia Amador, El proceso colaborativo en la construcción de la dramaturgia escénica del unipersonal sobre Mi casa una nube roja (2015) de Aysha Morales y Ya no son las mismas flores, versión libre de La Casa de Bernarda Alba, de Federico García Lorca: creación de una puesta en escena a partir de la dramaturgia escénica (2016) de Natalia Mariño. Amador (2010), a partir del texto expresionista Woyzeck (1836) del dramaturgo alemán George Büchner (1813- 1837) se propone realizar una versión monologada para el personaje femenino María, víctima del drama de Büchner. Amador plantea un procedimiento escritural compuesto por tres insumos: la metodología psicoanalítica de estudio de textos literarios: los tres lectores del psicoanálisis, propuesta por Baños Orellana en El escritorio de Lacan (1999), el análisis de la acción dramática, planteado por Vladich y Bonilla en Artes Dramáticas en la escuela (1981) y el trabajo 
escénico con una actriz. Morales (2015), por su parte, realiza su búsqueda dramatúrgica para la escritura de un monólogo, también, pero enfatizando la integración del equipo creativo (diseñadores, actuación y dirección) al proceso mediante la implementación de un proceso colaborativo. Esto con la premisa de que "la creación escénica es en sí misma una metodología investigativa que se presenta en el proceso y no le antecede" (Morales, 2015, p. vi). Finalmente, Mariño (2016), utiliza como detonante la obra del dramaturgo español Federico García Lorca (1898- 1936), La casa de Bernarda Alba (1936), para construir una versión libre del mismo, que se enfoca en el arte flamenco y la sexualidad femenina, articulados en la dramaturgia escénica.

Las autoras de estos trabajos coinciden en la disposición de la creación textual desde la dramaturgia escénica, cada una desde una búsqueda distinta propone una metodología para la creación de un texto dramático desde la escena, es decir que la escritura va apareciendo de forma paralela a la exploración escénica. Se considera importante recalcar que esta necesidad creativa de escribir desde la escena y la colectividad implican la necesidad de abordar el discurso desde el espacio y por consiguiente desde el cuerpo. Esta corporización de la escritura puede ser problemática a la hora de establecer mecanismos analíticos para su valoración académica. Morales en su definición del concepto de dramaturgia escénica establece la necesidad de entablar una relación horizontal entre los componentes escénicos, desde la concepción del espectáculo, y propone esta metodología de trabajo en oposición a la tradición:

Al hablar de Dramaturgia Escénica nos referimos a la operación dramatúrgica que se compone desde la totalidad de los elementos del lenguaje escénico, para concretar el acontecimiento teatral. Estos elementos teatrales son asumidos en el proceso creativo sin jerarquía alguna, oponiéndose a las formas tradicionales en las que se establece una relación de dependencia con el texto dramático, proporcionándole a éste un estatuto mayor tanto en la concepción como en la realización del espectáculo (Morales, 2015, p. 58).

En su trabajo Morales enfatiza sobre la metodología de trabajo y la necesidad de herramientas de sistematización del trabajo colaborativo. Mariño, por su parte, se encauza su abordaje en la necesidad de dialogar con el tema de la emancipación femenina:

decidí tomar la obra La Casa de Bernarda Alba de Federico García Lorca, que, a su manera, propone también ciertas perspectivas sobre la liberación/represión sexual femenina y las concepciones que se tenían en esa época. A partir de lo anterior, trabajaría en una reescritura desde un procedimiento en específico: la dramaturgia escénica (Mariño, 2016, p. 2) 
Mariño, al igual que Amador, manifiesta la intención de desarrollar un texto dramático a partir del punto de vista de la mujer. Sin embargo, en su caso, enfatiza la utilización del cuerpo de la actriz como herramienta para dirigir la búsqueda estética. La intención de Amador, mantener el estilo expresionista del que parte su búsqueda, contrasta con la operación estética que procura Mariño, donde el cuerpo femenino es privilegiado como propuesta discursiva, es decir, como abordaje temático.

El enfoque de trabajo de corte feminista, en cuanto a su escritura y articulado estéticamente desde el cuerpo, se proponen en el trabajo del Proyecto Teatral Emergencias, puntualmente en los trabajos de tres autoras, a saber: Elvia Amador (1981), Angie Cervantes (1980) y Milena Picado (1985), según recupera Albornoz (2007) en el artículo "Dramaturgia costarricense contemporánea emergente". Para el investigador la escritura de estas autoras comparte dos rasgos característicos: la intención de construir escénicamente un discurso político y la implementación de la dramaturgia escénica como herramienta articuladora de los componentes escénicos, donde el fenómeno teatral se aborda desde una perspectiva integral de producción, puesta en escena y publicación literaria.

En Emergencias, finalmente, desde escribir hasta actuar, pasando por dirigir, diseñar o producir, el arte escénico en su conjunto y específicamente la escritura dramática, enfrentadas individual y colectivamente, devienen todas formas de hacer y de pensar, oficios a través de cuya concreción se evidencia una opinión (Albornoz, 2007, p. 39).

Esta articulación, en los procesos de producción que atraviesan el fenómeno teatral, parece ser intrínseca a la filosofía detrás de la dramaturgia escénica donde se encarna la palabra desde su origen. En este aspecto de la creación integral en el teatro, o bien, el abordaje integral de la creación escénica, coinciden Amador, Mariño y Morales, citadas anteriormente en este texto, con Albornoz (2007) en sus conclusiones sobre las dramaturgias contemporáneas. Del mismo modo, propone el cuerpo como centro del material creativo:

Uno de los aspectos que más destaca como rasgo compartido por cada una de estas dramaturgas en sus respectivas ficciones es la instalación del cuerpo como material dramático central: el de los niños, dañado y muerto; el de las mujeres, expuesto y arrojado a la lucha/vida cotidiana; el de la adolescente, sobre el cual se disputan derechos y deberes (Albornoz, 2007, p. 40).

Así como el trabajo con el cuerpo, la estética de la violencia y su efecto en los individuos y sus relaciones el teatro planteado por las autoras Amador, Cervantes y Picado, se inscriben en el ámbito de lo político, según el académico Werner Mackenbach, citado por Albornoz. 
Es por eso que para él [Mackenbach], este teatro promete recuperar la función pública, cívica, crítica, activa y activadora de las tablas en el campo cultural costarricense y centroamericano, llamando a la reflexión, al distanciamiento, al rechazo o a cualquier otra reacción, es decir, al diálogo y no al consumo fácil y calmante (Albornoz, 2007, p. 41)

Dentro de esta misma tónica del rescate del teatro en el plano cultural y sus funciones: estética, ética y social; la académica y figura icónica del feminismo en el teatro costarricense: María Bonilla, en el texto La dramaturgia que inventó una identidad (2011), destaca la necesidad de abordar el fenómeno teatral como un espacio de construcción poética multidimensional, donde el hecho teatral es una estructura estético-ideológica. Asimismo, apunta el cambio constitutivo que surge contemporáneamente en oposición a la tradición:

Para muchos y durante muchos siglos, el autor y su obra constituyeron el elemento central, si no el primordial, entre los demás. Para otros y más contemporáneamente, es uno de los elementos, que al igual que el resto, conforman el fenómeno teatral (Bonilla, 2011, p. 3).

Bonilla (2011) hace énfasis en la dualidad artística presente en el teatro: posibilidades dicotómicas literario-dramática y escénico-teatral. Aclara que estas dicotomías pueden experimentarse de forma separada en cuanto a tiempos, recursos y procesos o bien de forma integral como en las producciones de dramaturgia escénica que se mencionaron anteriormente. En este texto Bonilla se ocupa de las imágenes literario- dramáticas; es decir, en el potencial expresivo de las imágenes que los autores o autoras literarios proponen en sus textos teatrales escritos. El discurso que atraviesa esta breve revisión es la construcción identitaria que el teatro posibilita en la construcción discursiva de las imágenes y su consecuente representación simbólica, encarnada en el hecho teatral. Igualmente, el estudio establece la importancia del rescate de la dramaturgia, en tanto encierra las formas de representación simbólica de la identidad costarricense (puntos de vista y formas de hacer y de conocer la realidad). Del mismo modo, señala la relevancia de grupos editoriales independientes que visibilicen el trabajo dramatúrgico como lo hace la Editorial Tinta en Serie, la cual publica este texto.

En esta línea de rescate de distintas perspectivas de la dramaturgia en Costa Rica, Tinta en Serie (2016), publica El drama de los dramaturgos, escribir teatro en la Costa Rica del siglo XXI. En él, se plantea la dificultad que significa para los dramaturgos ser publicados; motivo por el que se plantea su razón de ser, tomando en cuenta las necesidades contemporáneas, según ubica, donde no necesariamente el texto es preponderante. 
Al cabo de siete años en esta labor, ya hemos publicado cuarenta libros y abierto varias colecciones sobre áreas más específicas que atañen a la dramaturgia contemporánea (la crítica y la teoría teatral, la producción meta dramatúrgica, la escritura colectiva y experimental adherida a talleres y procesos de montaje, la trastienda teatral) (Arroyo, Istarú, Méndez, Morera \& Ramos, 2016, p. 3).

El libro es un compendio de cinco entrevistas que procuran orientar algunas claves de la producción dramatúrgica contemporánea, aunque según la revisión anterior y el término contemporáneo, de la forma que se acuña en la presente investigación, tiene otras implicaciones. No obstante, describe, de alguna manera, la conciencia de esta posible problematización, ya que se aclara que la selección de los dramaturgos entrevistados se realizó teniendo en cuenta su trayectoria y les ubica en la segunda generación de autores después de la Segunda Guerra Mundial, periodo en que las vanguardias artísticas están en auge. Dentro del desarrollo de las entrevistas se aborda la dramaturgia feminista en Costa Rica, a lo que los diferentes dramaturgos consultados se refieren desde distintos ángulos. Jorge Arroyo (1959-) posiciona su escritura como feminista, al lado de otros escritores como Alberto Cañas, repara en que sus textos rescatan "las preocupaciones de las mujeres" y, del mismo modo, subraya que la dramaturgia femenina no es necesariamente escrita por mujeres.

Ana Istarú (1960-) contrapone al adjetivo de feminista el de antipatriarcalista y reconoce el trabajo de algunos dramaturgos varones en esta línea, Melvin Méndez (1958-) comparte esta posición. Aylin Morera (1965-), por el contrario, afirma que existe dramaturgia feminista, pero problematiza su acepción argumentando que no toda la dramaturgia escrita por mujeres tiene una propuesta feminista. Finalmente, Arnoldo Ramos (1965-), manifiesta dificultad de precisar los límites del concepto dramaturgia feminista por lo que se reserva cualquier aseveración.

El poder es una característica de las relaciones y una condición que depende del contexto en que se da, pero resulta un gesto simbólico, por tanto, su valoración desde el arte dramático puede ser útil en tanto construcción y no únicamente como lugar de enunciación. En esta diferenciación recae el contraste en las posiciones de los dramaturgos citados en el texto de Tinta en Serie (2016) y la argumentación sostenida en el presente documento. Ahora bien, se admite una hipótesis sobre los patrones narrativos y si estos responden, o no, a las condiciones patriarcales del poder que se sostiene, por ejemplo, en la construcción de subjetividades sobre la que teoriza Fumero y que respalda Mackenbach citado en Albornoz. 


\section{Conclusiones: la dramaturgia costarricense de mujeres y su devenir contemporáneo}

El presente siglo organiza la separación del mundo de la palabra y el de la imagen. A esto se suman la disolución del sujeto en el tiempo, las nociones de historia como discursividad y la comprensión de la inevitabilidad del lenguaje para el pensamiento. Estos elementos generan una crisis en la representación y en la significación que tensan el concepto de creación en el arte, cambian la valoración del lenguaje artístico, promueven un desplazamiento de la obra y el texto y cuestionan la dualidad de las nociones sujeto-objeto y mente-mundo. En el teatro, con la llegada de las vanguardias artísticas, se evidencian todas estas crisis de forma escénica. Ahora bien, dentro de la dramaturgia costarricense, se encuentra una relación entre el concepto de lo siniestro y el de la escritura dramática femenina, ya que la mujer, desde un lugar epistemológico marginal, con frecuencia se ha posicionado en el lugar de lo simbólico para defender su discurso, incluso a nivel político. Este lenguaje, el simbólico, ha servido a la mujer de trinchera ante el poder hegemónico patriarcal. En este sentido, Bonilla (2016) apunta en Cartografía de una creación, conferencia impartida en Cuidad de México dentro del Coloquio "Improvisar en tiempos atroces":

creo que la producción femenina es crónica de una cultura y de una realidad donde no hay memoria, porque la memoria ha resultado para las mujeres un olvido voluntario, una realidad que al estar inscrita en las relaciones de poder vive impregnada de miedo y silencio, la mujer es lo excluido, aquello que ha sido colocado en la marginalidad, en el borde y que necesita antes que cualquier cosa incluirse, nombrarse, decirse (Bonilla, 2016).

Este enfoque político de la creación femenina permite pensar que las representaciones que hacen las mujeres, con frecuencia, se abordan desde este lugar de marginalidad. Por tanto, en sus construcciones simbólicas, se permite nombrar lo innombrable, habitar el silencio, es posible en las construcciones escénicas porque se trabaja construyendo vacíos en la narración para que el público los elabore, o llene, con su propio pensamiento, o experiencia. Vale la pena señalar también, en esta exposición de Bonilla (2016), la importancia que tienen para la escritura femenina los elementos memoria y olvido. Estos conceptos se inscriben dentro de la experiencia de la sistematización temporal que hemos identificado como sospecha dentro del discurso de lo contemporáneo que se percibe en autores que trabajan sobre la escritura dramatúrgica costarricense de mujeres, anteriormente mencionados.

"Creo que es tonto, que es una idea del sistema capitalista, hacernos creer que el éxito real de un artista es acceder los centros metropolitanos de la cultura. Podemos pensar que el centro somos nosotros y lo que estamos haciendo es importante aquí" (Ana Istarú en Arroyo et al., 2016). Este planteamiento de Istarú guarda relación intrínseca con esta 
posición contrahegemónica que nos posibilita la comprensión del problema de las creaciones artísticas de las mujeres y sus construcciones por ejemplo de la temporalidad y el posicionamiento del cuerpo como centro.

El rescate y la búsqueda de la construcción poética de las dramaturgas, en tanto marginal y simbólica, parecen ser entonces, más que una misión historicista, una necesaria reivindicación y visualización del papel de la mujer en este combate contra hegemónico. Pensando en cómo se transforma el arte, a partir de desplazamientos de contextualización y descontextualización, como propone ya el giro hermenéutico, se visualiza a partir de este estudio que la única manera de que la mujer tenga un lugar real en la construcción del lenguaje y el poder es a partir de lo simbólico como posibilidad de flexibilizar el lenguaje.

El trabajo dramatúrgico femenino funciona con palabras de mujer, con construcciones o patrones de pensamiento generados desde un lugar epistémico marginal, en las coordenadas del poder y, por lo tanto, su intención de "hacer presente lo ausente" ocurre a través de lo oculto, de lo secreto y lo siniestro. Al trabajar con este tipo de imágenes se construyen muchas identidades femeninas posibles siempre enfrentando un discurso patriarcal, develando una realidad o una parte de la realidad de forma física y tangible a partir de un discurso "escrito en la escena". Este discurso al insertarse en el discurso desde una posición alterna respecto al poder adquiere inevitablemente un carácter político.

Los discursos femeninos que surgieron como respuesta a su posición frente al poder y con más razón, los que fueron de alguna forma invisivilizados o censurados, son la historia imperceptible de una voz poética, de raíz política, en tanto el lugar de su enunciación es políticamente incorrecto. Estos enunciados se reafirman según coinciden las dramaturgias contemporáneas contenidas en los textos aquí investigados en cuanto a su tendencia por escribir sobre los temas sociales y políticos "desde los ojos de la mujer". Es decir "el lugar de enunciación mujer" que es el tema preponderante de su dramaturgia, es emprendedoramente político y procura apropiarse del espacio del discurso desde el espacio de la escena, es decir representando realidades probablemente para imaginar posibilidades.

Los cambios en las políticas culturales iniciados en la década de 1990 que rompió con la posición homogeneizante de los Estados nacionales y los giros culturales y subjetivos, unidos al cambio en el Estado han producido nuevas formas de percibir, entender y producir arte. La creciente producción de textos dramáticos en la región es un ejemplo de las posibilidades que implica el cambio en las premisas y los criterios de "canonización", valoración y reconocimiento de todo tipo de producciones culturales. Por tanto, vemos mayores posibilidades de acceder a los espacios de 
representación, promoción y análisis de la diversidad cultural, lo cual a su vez supone reconocer valores culturales de diversos grupos étnicos, etarios, genéricos y sociales (Fumero, 2009, párr. 3)

A partir de los textos estudiados, podemos concluir que son constitutivos de la escritura costarricense contemporánea de mujeres: el tratamiento estético de lo siniestro y lo político abordado desde el cuerpo. Ambos elementos son señalados por diferentes autores como Fumero y Morera que coinciden en los hallazgos desde dos enfoques distintos. El de Fumero (2008), desde un punto de vista más histórico, en el cual profundiza en los elementos simbólicos como apropiaciones teórico-culturales. Por su parte, Morera (2006) desde una perspectiva más semiótica, asociada a la construcción de imágenes para la representación y sus implicaciones políticas. Ambas visiones comprendidas como respuesta a la crisis de la subjetividad que se vive a principios del presente siglo.

Actualmente, al verse como performatividad, el poder, el tiempo y el género aparecen como nuevas perspectivas simbólicas, otras posibilidades de construcción de subjetividades. Tal vez desde las propias obras surjan categorías analíticas que nos libren de destinar a la escritura de las mujeres el ser valoradas como una esencia destilada desde la marginalidad. Se coincide con Albornoz en cuanto al compromiso y la posición en que estas características, que en el presente texto se le atañen, colocan a la escritura contemporánea de mujeres en el presente siglo, por cuanto ameritan la apropiación del lenguaje poético y habilitan el mundo poético como conquista femenina:

El teatro, y específicamente la dramaturgia, devienen, entonces, no solo un modo de expresión personal sino, también, y por lo menos, una práctica de resistencia o de combate para una emergente generación de mujeres costarricenses de teatro. Esto implica un compromiso y un riesgo, por los cuales han dado la cara y a los cuales han puesto su firma (Albornoz, 2009, p. 42).

El cuestionamiento de las posibilidades del teatro como manifestación contemporánea suponen la búsqueda de nuevos lenguajes narrativos que se integran para provocar rupturas o transformaciones en sus elementos constitutivos: cuerpo, espacio, tiempo, palabra, entre otros. La dramaturgia escénica de mujeres busca nuevas maneras de representar el mundo porque busca nuevos espacios, lugares de enunciación que le permitan habitar el espacio del discurso de otra manera, construyendo uno alternativo al que propone el discurso hegemónico-patriarcal, al que combate con imágenes potentes de mujeres poderosas que muchas veces rompen el silencio con el espejo y otras tantas con la escenificación. 
Asimismo, para generar movimiento en la concepción del mundo, el ser humano debe ser capaz de imaginar un mundo distinto y, quizás, la manera de integrar la visión de la mujer en esa concepción pase por el desplazamiento de la noción de significación a la de sentido, si partimos de lo simbólico para su integración o incorporación a nivel cognitivo y, por tanto, pragmático. "Toda producción de imágenes es la necesidad de definir y vincularse con un tiempo, un espacio, una cultura en particular, que parte de una pregunta del creador sobre su mundo, su época, su geografía o sobre sí mismo y lo que es, para él, el otro" (Bonilla, 2016). Podríamos decir, entonces, que el discurso dramatúrgico nacional de mujeres tiene una historia congruente, donde la premisa sigue siendo la misma, una respuesta emancipadora del poder patriarcal. Su evolución consiste en el espacio de la enunciación donde el universo político y su crisis se viven a partir del ocultamiento que se expone desde la subjetividad del cuerpo.

\section{Referencias}

Albornoz, A. (2009). Dramaturgia costarricense contemporánea emergente. Revista ESCENA, 32(64), 37- 44.

Amador, E. (2010). ¡Qué roja está la luna! (tesis para optar por el grado de Licenciatura en Artes Dramáticas). Universidad de Costa Rica, San José.

Arroyo, J.; Istarú, A.; Méndez, M.; Morera, A. \& Ramos, A. (2016). El drama de los dramaturgos/ Escribir teatro en la Costa Rica del siglo XXI. En Soto, R., Lázaro, L., Bonilla, M., Phillips, M., Solera, I., Teoría y crítica teatral (Vol. 3). San José: Editorial Tinta en Serie.

Bonilla, M. (2016). Cartografía de una creación en el Coloquio "Improvisar en tiempos atroces". Recuperado de https://www.youtube.com/watch?v=TY8nL_NN14A

Bonilla, M. (2011). La dramaturgia que inventó una identidad. San José: Editorial Tinta en Serie.

Calderón, J. (2004-2005). Aportes para una historiografía del teatro costarricense: ¿cómo y desde qué perspectiva se ha escrito la historia del teatro en nuestro país? Revista Estudios, (18-19), 63-69.

Castro, D. y Guevara, A. (2015). "El Baile de los Diablitos" en Boruca: Magia vrs. Dominación. Revista Herencia, 28(2), 65-80.

Cohen, D. (2014). ¿Para bien de... quién? La mentira, la manipulación psicológica y las relaciones afectivas en dos obras del teatro costarricense contemporáneo? Revista Estudios, (29), 1-11.

ESCENA. Revista de las artes, 2019, Vol. 79, Núm. 1 (julio-diciembre), pp. 275-301 
Foucault, M. (1988). El sujeto y el poder. Revista mexicana de sociología, 50(3), 3-20.

Fumero, P. (2009). Teatro Centroamericano, Introducción. ISTMO. Revista virtual de estudios literarios y culturales, (18). Recuperado de http://istmo.denison.edu/n18/ articulos/intro.html

Fumero, P. (2008). Femineidades emergentes, a propósito de emergencias: dramaturgias contemporáneas emergentes. Revista ESCENA, 31(63), 85-90.

Fumero, P. (2007). Los caminos de la dramaturgia costarricense. Revista ESCENA, 30(60), 85-90.

Gadamer, H. (2011). Estética y hermenéutica. Madrid: Tecnos.

Lázaro, L. (2014). Mito, género y empresa tres imágenes originarias de la dramaturgia contemporánea costarricense. ESCENA. Revista de las artes, 74(1), 21-27.

Mariño, N. (2016). Ya no son las mismas flores, versión libre de La Casa de Bernarda Alba, de Federico García Lorca: creación de una puesta en escena a partir de la dramaturgia escénica (tesis para optar por el grado de Licenciatura en Artes Dramáticas). Universidad de Costa Rica, San José.

Miller, E. (2011). Las contradicciones de ser mujer en Costa Rica en el siglo XXI en la dramaturgia emergente: El cuerpo femenino en Sinapsis (cuatro locas masticando a un imbécil) de Elvia Amador y 100 gramos de Janil Johnson. Letras Femeninas, 37(1), 125-137. Recuperado de: http://www.jstor.org/stable/23021848

Morales, A. (2015). El proceso colaborativo en la construcción de la dramaturgia escénica del unipersonal sobre Mi casa una nube roja (tesis para optar por el grado de Licenciatura en Artes Dramáticas). Universidad de Costa Rica, San José.

Morera, A. (2006). La escritura femenina. Deconstruyendo imágenes. Conjunto. Revista de teatro latinoamericano, (139), 68-71.

Pavis, P. (2016). Diccionario de la performance y del teatro contemporáneo. Ciudad de México: Ediciones y Producciones Escénicas y cinematográficas.

Quesada, A.; Ovares, F.; Rojas, M. \& Santander, C. (1993). Antología del teatro costarricense, 1890-1950. San José: Editorial de la Universidad de Costa Rica.

Soto, R. (2014). Lo siniestro y el cambio de modelo político en Costa Rica: tres obras teatrales de autoras contemporáneas. ESCENA. Revista de las artes, 74(1), 21-27.

Wyss, B. (2010). La voluntad de arte. Madrid: Abada. 